\title{
Patterns and Predictors of Proton Pump Inhibitor Overuse among Academic and Non-Academic Hospitalists
}

\author{
Shaker M. Eid ${ }^{1}$, Adel Boueiz ${ }^{2}$, Suchitra Paranji ${ }^{3}$, Christine Mativo ${ }^{1}$, \\ Regina Landis BA ${ }^{1}$ and Marwan S. Abougergi ${ }^{1}$
}

\begin{abstract}
Objective In the hospital setting, several studies have reported proton pump inhibitor (PPI) overuse, a majority of which is continued after discharge. In addition to being expensive, PPIs are associated with an increased risk of infections, osteoporosis and serious drug interactions. We examined the trends and predictors of PPI guidelines non-compliance among academic and non- academic hospitalists in USA.

Methods and Patients Oral PPI prescriptions initiated by 2 academic and 2 non-academic hospitalist groups were reviewed. Prescription indications were recorded when explicitly stated in the chart. Otherwise, qualified physicians reviewed the chart to make such determination. Indications were then compared to the published guidelines. Several variables were tested to determine independent predictors of initiation and post discharge continuation of guideline non-compliant prescriptions.

Results Of the 400 PPI prescriptions 39\% were guideline compliant. Academic hospitalists were significantly more compliant with PPI prescription guidelines (50 vs 29\%). Gastrointestinal ulcer bleeding prophylaxis (GIP) for low risk patients was the most common indication for non-compliant prescriptions, while that of guideline compliant prescriptions was dyspepsia treatment. Independent predictors of the initiation of guideline non-compliant prescriptions were non-academic hospitalist group, PPI indication not documented in the chart, and GIP as part of the admission orderset. The latter was an independent predictor of those prescriptions continuation post-discharge (protective) in addition to non-academic hospitalists group.

Conclusion Hospitalists overprescribe PPI to a level comparable to that of the non-hospitalist providers in the literature. Understanding the determinants of increased compliance among academic groups is instrumental to design interventions aimed at increasing PPI prescription compliance.
\end{abstract}

Key words: proton pump inhibitors, guideline adherence/statistics and numerical data, health services misuse/ statistics and numerical data, drug utilization/statistics and numerical data, medical audit

(Intern Med 49: 2561-2568, 2010)

(DOI: 10.2169/internalmedicine.49.4064)

\section{Introduction}

In an era of heated healthcare reform debate about the cost and safety of healthcare delivery, it is important to address all sources of inappropriate healthcare expenditure (1). As our healthcare system and its incentives continue to progress toward alignment with value-based high-quality care in the hospital setting, hospitalists are called upon to lead change to transform the system to one that provides highvalue safe care for all (2). Several studies have documented that the hospitalist model has had a significant impact on hospitals' healthcare quality and is associated with better performance on many Hospital Quality Alliance (HQA) indicators, hospital length of stay, and ED throughput among other quality improvement measures (3-5).

Since the introduction of the first proton pump inhibitor (PPI) in the late 1980's, the use of PPIs has increased expo-

${ }^{1}$ Department of Internal Medicine, Johns Hopkins School of Medicine, Johns Hopkins Bayview Medical Center, Baltimore, U.S.A., ${ }^{2}$ Department of Internal Medicine, Johns Hopkins School of Medicine, Baltimore, U.S.A. and ${ }^{3}$ Department of Internal Medicine, Good Samaritan Hospital of Maryland, Baltimore, U.S.A.

Received for publication June 9, 2010; Accepted for publication August 4, 2010

Correspondence to Dr. Marwan Abougergi, mabouge1@jhmi.edu 
nentially with sharp increases of up to $456 \%$ in the 1990's relative to earlier years (6). PPIs remain one of the world's most frequently prescribed medications (7); concurrently, several studies in the United States and Europe continue to report PPI overuse in the hospital and ambulatory settings. For instance, in the hospital setting, compliance with established PPI prescription guidelines was reported to be as low as $19 \%$ (8). Furthermore, once PPIs are started in-hospital, previous reports show that more than $50 \%$ of patients continue to take them 3 to 6 months after discharge (9-11).

Although PPIs are generally perceived as safe medications, several reports in the medical literature, mostly case control studies and large population based reports, continue to debate their possible side effects. Laheij et al showed that the adjusted relative risk for community-acquired pneumonia among PPI users compared to non-users is 1.89 (12). Cunningham et al reported a more than two-fold increase in the odds of contracting Clostridium difficile colitis in the same patient population (13). In two recent case-control studies (14-16), the odds ratio of osteoporosis-related fractures were 1.44 to 2.65 in patients receiving PPI compared to those who are not. Concerns that therapy with PPIs may mask signs of gastric cancer or even induce precursors of intestinal metaplasia have also been raised. However, unlike animal studies, this has not been fully substantiated in humans (17-19). Moreover, multiple recent studies have questioned the safety of concomitant use of PPI with Clopidogrel in patients with severe cardiac disease and post-PCI. This is because of the increased incidence of cardiovascular events in this patient population reported in some studies (20-22), although data from propensity matched or trial participants failed to show the risk of co-administrating these two classes of drugs (23).

Therefore, increasing compliance to PPI prescription guidelines seems to be an important step that can potentially decrease both the risk of side effects and healthcare cost. To date, little has been published with regards to specific predictors of non-compliance with PPI prescription guidelines in the hospital as well as the predictors for continuation of such prescriptions upon discharge. Thus, we sought to study those factors among hospitalists, both academic and nonacademic, due to the potentially important role they can play in rectifying the problem.

\section{Methods}

\section{Study design and study population}

The study population was derived from patients of four hospitalist groups in four teaching medical centers in the state of Maryland: two were academic and two were nonacademic. A hospitalist group was classified as academic if the hospitalists were involved in teaching and research in addition to patient care. Otherwise, the group was classified as non-academic. Academic groups 1 and 2 included 24 and 14 hospitalists respectively, whereas non-academic groups 1 and 2 included 9 and 8 hospitalists respectively.

A total of 100 consecutive PPI prescriptions were reviewed retrospectively in each center. Patients on the hospitalist service, 21 years and older, who received at least one dose of an oral PPI while in one of the four study centers, were identified using the pharmacy database. Patients were excluded if they were taking any kind of gastric acid suppressant before admission to the hospital (antacids, histamine receptor blockers, PPI or cytoprotective agents like sucralfate, misoprostol or bismuth subsalicylate). Once patients were identified, the charts were reviewed to identify the indication for the PPI prescription. When this indication was not explicitly documented, two trained physicians reviewed the whole chart to ascertain if any approved indication applied to the patient. If so, the indication was entered in the database and the prescription was classified as guideline compliant. Otherwise, the prescription was classified as guideline non-compliant and the most likely indication was entered into the database. Both reviewers were blinded to the hospitalist group who treated the patient. In order to minimize inter-observer variability, the reviewers scored 15 charts independently and then went over each chart together. When the scores were different ( 1 out of 15 ), they discussed the reasons behind their decision and fine-tuned the algorithm used. PPI prescription guidelines were identified from the Food and Drug Administration (FDA), American Gastroenterological Association (AGA), the American College of Gastroenterology (ACG) and the American Society of Health-System Pharmacists (ASHP) publications and position papers on the topic (24-27) (Fig. 1). Demographics as well as other patient characteristics were also collected. A patient was considered at low risk for gastric ulcer bleeding if he/she did not have any of the risk factors that warrant initiation of gastrointestinal ulcer bleeding prophylaxis listed in Fig. 1. The study was approved by the Johns Hopkins and Medstar institutional review boards.

\section{Outcomes measured}

The main outcome of the study was the percent compliance with the PPI guidelines among academic and nonacademic hospitalist groups. The secondary outcome was the identification of independent predictors of both guideline non-compliant PPI initiations in the hospital and PPI continuations upon discharge.

\section{Statistical analysis}

Based on the results of a pilot we performed at the four institutions, the study was powered at $80 \%$ with an alpha of 0.05 to detect a $15 \%$ difference between the academic and non-academic study groups' guideline compliance rates. The former was estimated to be $55 \%$ based on the same pilot results. Two-sided statistical tests were performed at an alpha level of 0.05 . Fisher exact test and student's $t$-test were used to compare proportions and means, respectively. Univariate and multivariate logistic regression analyses were used to identify independent predictors of PPI guideline non- 


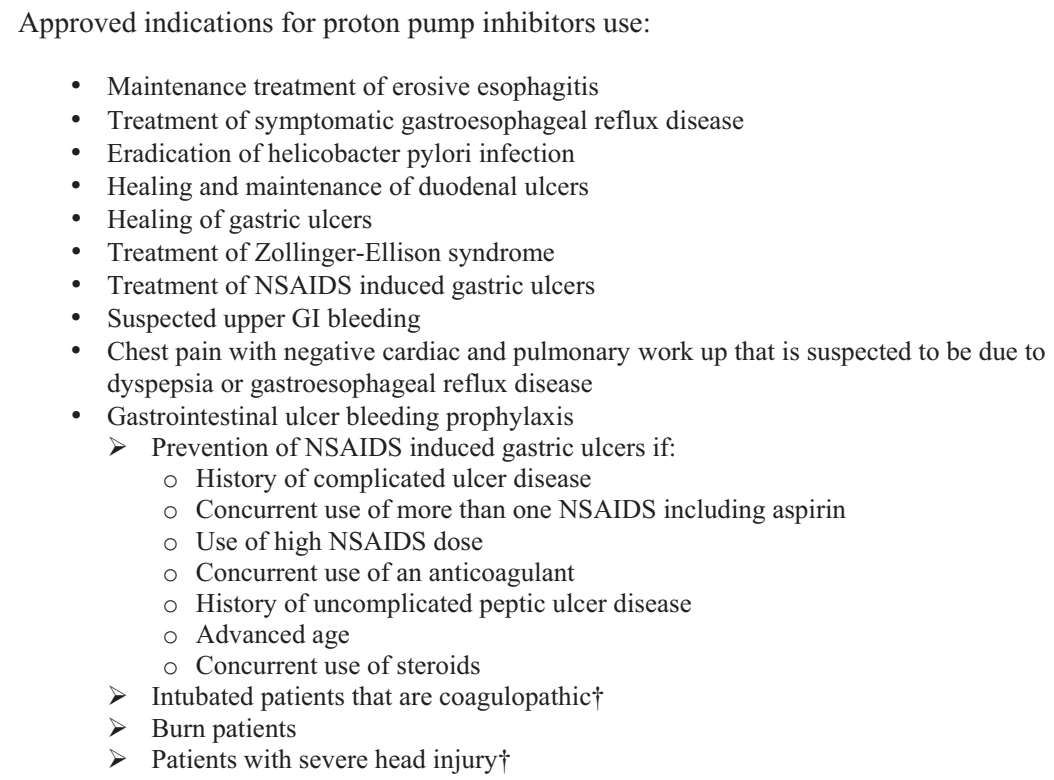

Figure 1. Prescription guidelines for proton pump inhibitors used in this study to measure compliance among academic and non-academic hospitalists. (24-27) $\dagger$ : Patients in intensive care units were excluded from the study, thus those parameters were not applicable to the study patients.

Table 1. Percentage of Guidelines Compliant Proton Pump Inhibitor Prescriptions

\begin{tabular}{rcccc}
\hline & Total (\%) & Academic (\%) & Non-academic (\%) & p value \\
\hline Guidelines compliant & $156(39 \%)$ & $200(50 \%)$ & $116(29 \%)$ & $<0.05$ \\
Guidelines non-compliant & $244(61 \%)$ & $200(50 \%)$ & $284(71 \%)$ & \\
\hline
\end{tabular}

compliance among the collected variables as well as PPI presence on the discharge sheet among guideline noncompliant prescriptions. Multivariate logistic regression models included all variables that were statistically significant in unadjusted analyses, were considered clinically important, or whose addition to the models substantially changed the estimates of the effect of other factors. All analyses were conducted using STATA version (11).

\section{Results}

\section{Study Participants Characteristics}

Participants were 400 patients, 100 from each medical center. The mean age was 56 years (standard deviation, S.D. $=18$ ), and $51 \%$ were males. $11 \%$ and $22 \%$ were receiving PPIs with either anticoagulants or NSAIDS, respectively. 7\% of patients had a history of GI bleed. There was no statistically significant difference in the distribution of each variable among academic and non-academic hospitalist groups in the current study, except for mean age (58 years for nonacademic hospitalist patients versus 54 for academic ones, $\mathrm{p}=0.02$ ) and concurrent use of NSAIDS (38\% for nonacademic hospitalist patients vs. $6 \%$ for academic ones, $\mathrm{p}<$ $0.05)$.

\section{Compliance with PPI prescription guidelines}

Overall, 39\% of the total PPI prescriptions initiated in the four centers were compliant with the published guidelines. Prescriptions initiated by academic hospitalists were significantly more likely to be compliant with the guidelines compared to those initiated by non-academic hospitalists included in this study (50\% vs 29\%, p<0.05) (Table 1).

\section{Indications for PPI prescriptions}

Figure 2 summarizes the indications for PPI prescriptions among academic and non-academic hospitalist groups in our study. Among guideline non-compliant prescriptions, gastrointestinal ulcer bleeding prophylaxis (GIP) was the leading indication accounting for $82 \%$ of all such prescriptions initiated by academic (63\%) and non-academic (96\%) hospitalist groups $(\mathrm{p}<0.05)$. On the other hand, dyspepsia was the most common indication for all guideline-compliant prescriptions and those initiated by academic hospitalists, while GIP was the leading indication for prescriptions started by nonacademic hospitalists.

\section{Patients' characteristics for guideline compliant vs. guideline non-compliant prescriptions}

Patients who received guideline compliant prescriptions were significantly more likely to have the PPI listed on the discharge medication list and its indication documented in 


\section{All Hospitalists:}

Compliant prescriptions

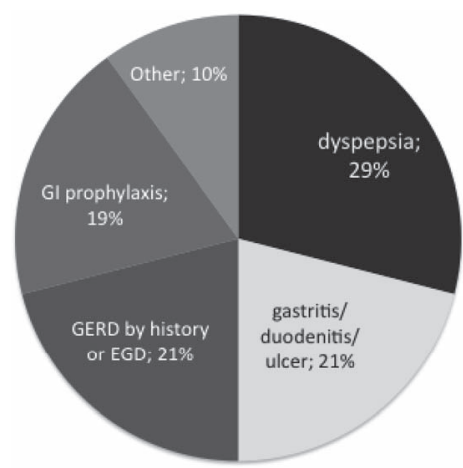

Academic hospitalists:

Compliant prescriptions

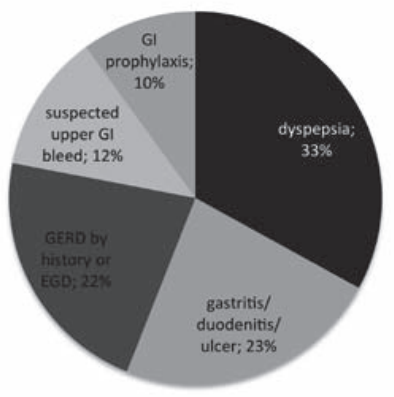

Non- academic hospitalists:

Compliant prescriptions

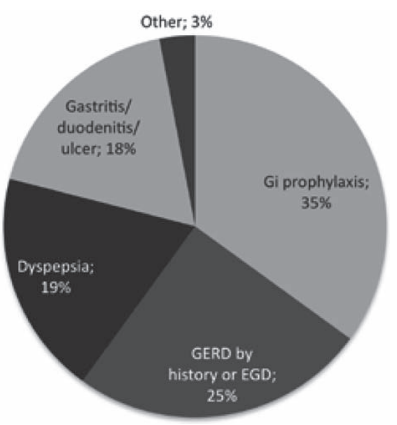

Non-compliant prescriptions

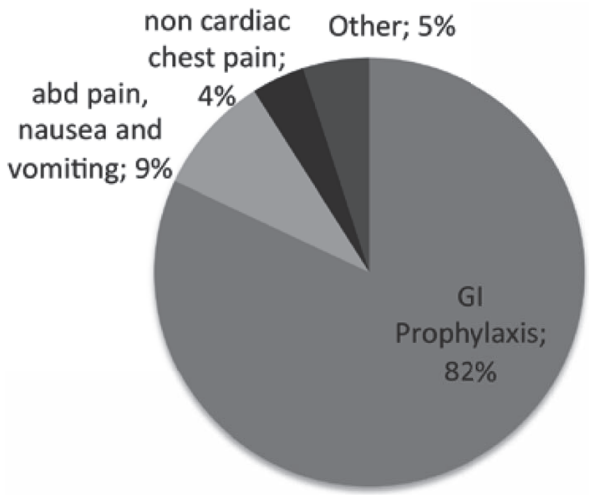

Non-compliant prescriptions

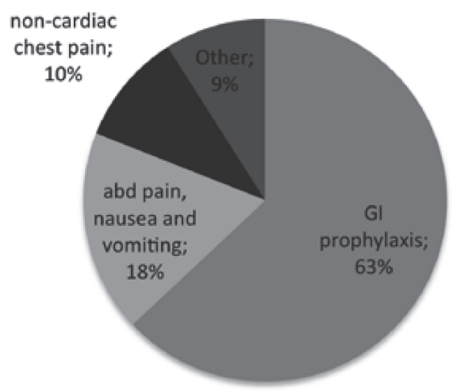

Non-compliant prescriptions

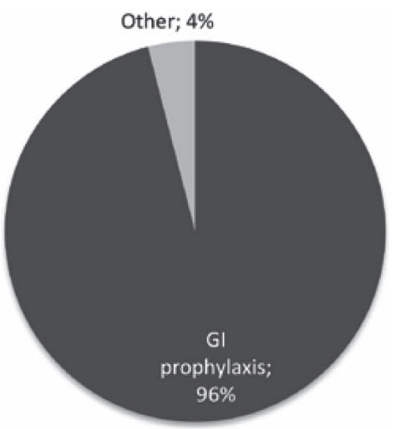

Figure 2. Indications for guidelines compliant and non-compliant proton pump inhibitor prescriptions. GI: Gastrointestinal, GERD: Gastroesophageal reflux disease, EGD: Esophagogastroduodenoscopy, abd: Abdominal

the chart compared to those who received guideline noncompliant prescriptions. Those two populations did not differ with respect to several other collected characteristics, as shown in Table 2.

\section{Independent predictors of guideline non-compliant PPI prescriptions}

Among the different variables tested, only the following three were found to be statistically significant independent predictors of guideline non-compliance when tested indi- vidually: concomitant use of anticoagulants (protective effect), prescription being initiated by a non-academic hospitalist group in our study, and PPI indication not documented in the chart (Table 3). After adjusting for all the other variables, those three factors remained significant independent predictors of non-compliance in addition to concomitant use of non-steroidal anti-inflammatory drugs (NSAIDS) (protective effect) and the presence of a checkbox for GIP order on the admission orderset. 
Table 2. Patient Characteristics for Guideline Compliant vs. Non-compliant Prescriptions

\begin{tabular}{|c|c|c|c|}
\hline & $\begin{array}{c}\text { Compliant }(\%) \\
n=156\end{array}$ & $\begin{array}{c}\text { Non compliant (\%) } \\
\mathrm{n}=244\end{array}$ & $\mathrm{p}$ value \\
\hline Age & $56(17) \dagger$ & $56(18) \dagger$ & 1 \\
\hline Female to Male Ratio & $71 / 85$ & $124 / 120$ & 0.302 \\
\hline Concomitant use of anticoagulants & $25(16 \%)$ & $22(9 \%)$ & 0.037 \\
\hline Concomitant use of NSAIDS & $3623 \%)$ & $42(17 \%)$ & 0.241 \\
\hline Patient discharged home & $141(90 \%)$ & $206(84 \%)$ & 0.204 \\
\hline Attending of record started PPI & $45(29 \%)$ & $66(27 \%)$ & 0.801 \\
\hline History of GI bleed & $16(10 \%)$ & $123(5 \%)$ & 0.105 \\
\hline Patient discharged by admitting service & $153(98 . \%)$ & $239(98 \%)$ & 1 \\
\hline PPI listed on discharge medication list & $89(57 \%)$ & $68(28 \%)$ & $<0.05$ \\
\hline PPI indication documented in chart & $128(82 \%)$ & $158(65 \%)$ & 0.0003 \\
\hline
\end{tabular}

Table 3. Predictors of PPI Guidelines Non-compliance

\begin{tabular}{|c|c|c|c|c|c|c|}
\hline Variable & $\begin{array}{l}\text { Odds ratio } \\
\text { (single) }\end{array}$ & 95\% C.I. & $\mathrm{p}$ value & $\begin{array}{c}\text { Odds Ratio } \\
\text { (multiple) }\end{array}$ & 95\% C.I. & $\mathrm{p}$ value \\
\hline Age & 1 & $0.99-1.01$ & 0.9 & 1 & $0.99-1.01$ & 0.86 \\
\hline Male gender & 1.05 & $0.70-1.57$ & 0.7 & 0.88 & $0.57-1.36$ & 0.56 \\
\hline $\begin{array}{l}\text { Concomitant use of } \\
\text { anticoagulants }\end{array}$ & 0.43 & $0.23-0.81$ & 0.01 & 0.32 & $0.15-0.64$ & 0.001 \\
\hline $\begin{array}{l}\text { Concomitant use of } \\
\text { NSAIDS }\end{array}$ & 0.85 & $0.52-1.37$ & 0.51 & 0.37 & $0.20-0.67$ & 0.001 \\
\hline History of GI bleed & 0.58 & $0.27-1.27$ & 0.18 & 0.58 & $0.25-1.36$ & 0.21 \\
\hline $\begin{array}{l}\text { Non-academic hospitalist } \\
\text { group }\end{array}$ & 2.47 & $1.63-3.74$ & $<0.05$ & 2.95 & $1.66-5.23$ & $<0.05$ \\
\hline $\begin{array}{l}\text { PPI indication not } \\
\text { documented in the chart }\end{array}$ & 1.87 & $1.16-3.02$ & 0.01 & 2.62 & $1.55-4.42$ & $<0.05$ \\
\hline $\begin{array}{l}\text { GI prophylaxis as part of } \\
\text { the admission orderset }\end{array}$ & 2.38 & $1.44-3.96$ & $<0.05$ & 1.96 & $1.00-3.85$ & 0.049 \\
\hline Patient discharged home & 0.69 & $0.33-1.41$ & 0.31 & & & \\
\hline $\begin{array}{c}\text { Attending of records } \\
\text { started PPI }\end{array}$ & 0.8 & $0.48-1.34$ & 0.41 & & & \\
\hline
\end{tabular}

C.I. $=$ Confidence Interval. NSAIDS $=$ Non Steroidal Anti-Inflammatory Drugs. GI $=$

Gastrointestinal. PPI = Proton Pump Inhibitors.

\section{Independent predictors of PPI presence on the dis- charge medication list among guideline non- compliant prescriptions}

In order to determine which factors independently predicted PPI presence on the discharge medication list among guideline non-compliant prescriptions, single and multivariate logistic regression analysis models were constructed (Table 4). Only the presence of a checkbox for GIP order in the admission orderset was found to be an independent predictor (protective effect) of PPI presence on the discharge medication list. After adjusting for the other variables, the protective effect of the checkbox for GIP order remained significant, and in addition PPI prescription being initiated by a non-academic hospitalist group in the current study became a significant independent predictor.

\section{Discussion}

In the current study, the vast majority of PPI prescriptions initiated in the hospital were by non-academic hospitalists and half of those initiated by academic hospitalists were guideline non-compliant. The main indication for noncompliance was GIP for low risk patients. Predictors of noncompliance were PPI indication not documented in the chart, presence of a checkbox for GIP order on the admission orderset and PPI prescription being initiated by a nonacademic hospitalist group. The latter was also an independent predictor of guideline non-compliant PPI prescriptions presence on the discharge medication list.

Several retrospective studies in the United States and Europe examined the PPI prescribing behavior of different provider groups in teaching and non-teaching hospitals and clinics. Our study is the first one to target hospitalists, and to subdivide them into academic and non-academic groups. 
Table 4. Predictors of PPI Presence on the Discharge Medication List among Non-guideline Compliant Prescriptions

\begin{tabular}{|c|c|c|c|c|c|c|}
\hline Variable & $\begin{array}{l}\text { Odds ratio } \\
\text { (single) }\end{array}$ & 95\% C.I. & $\mathrm{p}$ value & $\begin{array}{c}\text { Odds Ratio } \\
\text { (Multiple) }\end{array}$ & 95\% C.I. & $\mathrm{p}$ value \\
\hline $\begin{array}{l}\text { PPI indication not } \\
\text { documented in the } \\
\text { chart }\end{array}$ & 0.93 & $0.53-1.64$ & 0.80 & 0.63 & $0.19-2.1$ & 0.45 \\
\hline $\begin{array}{c}\text { Attending of records } \\
\text { started PPI }\end{array}$ & 1.82 & $0.89-3.74$ & 0.1 & 1.84 & $0.57-5.95$ & 0.31 \\
\hline $\begin{array}{l}\text { Concomitant use of } \\
\text { anticoagulants }\end{array}$ & 0.59 & $0.21-1.71$ & 0.33 & 0.37 & $0.05-2.75$ & 0.33 \\
\hline History of GI bleed & 0.76 & $0.23-2.53$ & 0.65 & 1.09 & $0.15-7.93$ & 0.93 \\
\hline $\begin{array}{l}\text { Concomitant use of } \\
\text { NSAIDS }\end{array}$ & 0.77 & $0.40-1.50$ & 0.44 & 0.21 & $0.04-1.08$ & 0.06 \\
\hline $\begin{array}{l}\text { Patient discharged } \\
\text { home }\end{array}$ & 0.57 & $0.25-1.31$ & 0.19 & 0.50 & $0.13-1.94$ & 0.32 \\
\hline $\begin{array}{l}\text { Non-academic } \\
\text { hospitalist group }\end{array}$ & 1.18 & $0.69-2.03$ & 0.53 & 14.7 & $4.09-52.68$ & $<0.05$ \\
\hline $\begin{array}{l}\text { Patient discharged by } \\
\text { admitting team }\end{array}$ & 1 & $0.89-11.24$ & 1 & 0.17 & $0.01-3.71$ & 0.26 \\
\hline $\begin{array}{l}\text { GI prophylaxis as part } \\
\text { of the admission } \\
\text { orderset }\end{array}$ & 0.17 & $0.08-0.35$ & $<0.05$ & 0.13 & $0.001-0.12$ & $<0.05$ \\
\hline $\begin{array}{c}\text { Number of providers } \\
\text { per admission }\end{array}$ & 0.74 & $0.42-1.32$ & 0.31 & & & \\
\hline
\end{tabular}

C.I. $=$ Confidence Interval. PPI $=$ Proton Pump Inhibitors. NSAIDS $=$ Non Steroidal AntiInflammatory Drugs. GI = Gastrointestinal.

Hospitalists are a major prescriber group in the hospital setting; therefore, studies aimed at characterizing their prescribing behavior have the potential to inform interventions that can substantially impact PPI utilization. The current study is also among a few which identified independent predictors of initiation of guideline non-compliance and is the first to identify independent predictors of their continuation postdischarge.

The rate of guideline compliance among non-academic hospitalists was significantly lower than that of academic hospitalists in this study (29\% and $50 \%$, respectively). Both rates were within the range reported by other groups, namely $19 \%$ to $78 \%(8,10,11,28-39)$. GIP in low risk patients has also been identified in other studies as the major reason for non-compliance (38), in addition to relief of nonspecific abdominal symptoms $(33,35,39)$ or indeterminate chest pain (35), prevention of medication-associated complications (36) and mild forms of gastroesophageal reflux (30).

Four other studies have attempted to identify independent risk factors for non-compliance $(28,32,34,38)$, only two of which adjusted for possible confounding variables through multivariate logistic regression and found good functional status, a prescription initiated by a general practitioner, and a history of an endoscopy evaluation (38) as independent predictors of compliance with the PPI prescription guidelines. Age and gender, similar to our results, were not significant independent predictors (28).

We identified two system-based predictors of noncompliance, namely PPI indication not documented in the chart and checkbox for GIP as part of the admission orderset. Those should therefore be a focus for quality improve- ment projects aimed at PPI prescription compliance. We also identified for the first time two factors that increase compliance, namely concomitant use of anticoagulants and NSAIDS. Those, along with the other factors listed in Table 4 , can be used for cost-effectiveness analysis and intervention feasibility when planning such quality improvement projects.

Further, our results suggest that understanding the reason behind the increased compliance among academic hospitalists in our study compared to non-academic hospitalists is instrumental for designing effective interventions aimed at decreasing improper PPI use in the hospital. We have shown that this difference is independent of many variables listed in Table 4. Specifically, it persisted even after adjusting for patients' age and concomitant use of NSAIDS (both variables were statistically significantly different between the two types of hospitalists). For both types of hospitalist groups, correcting the behavior towards GIP seems to be the most important intervention as it accounted for $82 \%$ of guideline non-compliant prescriptions. This intervention seems to be even more important for non-academic hospitalist groups, since GIP accounted for almost all (96\%) guideline non-compliant prescriptions. Other potential interventions would be mandating documentation of the reason/indication for PPI use on admission and elimination of the check box for GIP on the admission orderset when present. The latter intervention, however, might have the unintended effect of increasing guideline non-compliant PPI prescriptions present on the discharge medication list as discussed below.

Continuation of guideline non-compliant PPI prescriptions 
after discharge was documented previously at rates of 50 to $65 \%$ on day 1 (9-11), $46 \% 3$ months post discharge (11) and $71 \% 6$ months post discharge (10). We have shown that guideline non-compliant PPI prescriptions are continued at an unacceptable rate $(28 \%)$, which remains however lower than that of the guideline compliant prescriptions $(56 \%)$ or that reported in the other above-mentioned studies. The only risk factor we identified is prescriptions written by nonacademic hospitalist groups. This emphasizes the importance of identifying the factors behind the difference in behavior between the two hospitalist groups in the current study to derive intervention plans. On the other hand, we identified the presence of a checkbox for GIP on the admission orderset as a protective factor. This might be because it reminded the discharging physician that the PPI was started specifically for GIP, and thus needed to be discontinued. Therefore, interventions aimed at removing the checkbox when present will have a dual effect: a decrease in noncompliance with PPI prescription guidelines as well as an increase in continuation of guideline non-compliant prescriptions after discharge. We expect the net effect to be a decrease in guideline non-compliant prescriptions being continued after discharge, because of the reduction in the overall non-compliant prescriptions available to be continued post discharge. Quality improvement project designers could consider coupling this intervention with one aimed at reminding the discharging physician to stop a PPI if it is noncompliant with the guidelines to increase its overall effectiveness. Handoffs between providers did not seem to be an important factor in discontinuation of guideline noncompliant PPI prescription post discharge, as the three variables measuring handoffs (attending of records started PPI, number of providers per admission, patient discharged by admitting team) were not statistically significant predictors.

The current study has several limitations. First, being retrospective in nature, we had to infer indications from the chart when they were not clearly stated. We counted the prescription as compliant if any approved indication applied to the patient. As the prescribing provider could have started the PPI for another, guideline non-compliant indication, inferring indications this way could have resulted in underestimation of the rate of guideline non-compliance, and therefore numbers presented here are a conservative estimate. Second, it could be argued that the results were biased by the prescribing habits of a relatively small number of physicians; however, all members in each hospitalist group contributed to initiating PPI prescriptions. In addition, each patient was seen by an average of 3 hospitalists during the hospital stay, giving each hospitalist the chance to stop the PPI even if he/she did not start it. Furthermore, our study results are consistent with those of previously published ones with several different designs. Third, our study population is derived from teaching centers in the state of Maryland, and therefore the results above might not apply to other types of centers in other states. Our method though, when applied to those types of centers, should lead to center specific results that can inform center specific interventions.

\section{Conclusion}

Despite more than a decade of literature addressing this issue, PPI over-prescription is still prevalent in the hospital setting in many countries in Europe and the United States. In the current study, non-academic hospitalists complied less with PPI prescription guidelines compared to academic ones, and it is the first to address the specific predictors of guideline non-compliant PPI prescription initiation and subsequent continuation upon discharge. The main indication for non-compliance was GIP for low risk patients. Predictors of non-compliance were PPI indication not documented in the chart, presence of a checkbox for GIP order in the admission orderset and PPI prescription being initiated by a nonacademic hospitalist group in our study. The latter is also an independent predictor of guideline non-compliant PPI prescriptions presence on the discharge medication list. Quality and safety improvement interventions are needed to reduce the excess cost and potential harm from PPI, and should target the factors listed above.

\section{References}

1. Cunningham PJ. The Growing Financial Burden Of Health Care: National And State Trends, 2001-2006. Health Aff (Millwood) 2010.

2. Conway PH. Value-driven health care: implications for hospitals and hospitalists. J Hosp Med 4: 507-511, 2009.

3. Howell E, Bessman E, Kravet S, Kolodner K, Marshall R, Wright $\mathrm{S}$. Active bed management by hospitalists and emergency department throughput. Ann Intern Med 149: 804-811, 2008.

4. Harrison JP, Curran L. The hospitalist model: does it enhance health care quality? J Health Care Finance 35: 22-34, 2009.

5. Lopez L, Hicks LS, Cohen AP, McKean S, Weissman JS. Hospitalists and the quality of care in hospitals. Arch Intern Med 169: 1389-1394, 2009.

6. Guda NM, Noonan M, Kreiner MJ, Partington S, Vakil N. Use of intravenous proton pump inhibitors in community practice: an explanation for the shortage? Am J Gastroenterol 99: 1233-1237, 2004.

7. Garner A, Fadlallah H, Parsons ME. 1976 and all That!--20 years of antisecretory therapy. Gut 39: 784-786, 1996.

8. Ntaios G, Chatzinikolaou A, Kaiafa G, Savopoulos C, Hatzitolios A, Karamitsos D. Evaluation of use of proton pump inhibitors in Greece. Eur J Intern Med 20: 171-173, 2009.

9. Nardino RJ, Vender RJ, Herbert PN. Overuse of acid-suppressive therapy in hospitalized patients. Am J Gastroenterol 95: 31183122, 2000.

10. Grant K, Al-Adhami N, Tordoff J, Livesey J, Barbezat G, Reith D. Continuation of proton pump inhibitors from hospital to community. Pharm World Sci 28: 189-193, 2006.

11. Parente F, Cucino C, Gallus S, et al. Hospital use of acidsuppressive medications and its fall-out on prescribing in general practice: a 1-month survey. Aliment Pharmacol Ther 17: 15031506, 2003.

12. Laheij RJ, Sturkenboom MC, Hassing RJ, Dieleman J, Stricker BH, Jansen JB. Risk of community-acquired pneumonia and use of gastric acid-suppressive drugs. JAMA 292: 1955-1960, 2004.

13. Cunningham R, Dale B, Undy B, Gaunt N. Proton pump inhibitors as a risk factor for Clostridium difficile diarrhoea. J Hosp Infect 54: 243-245, 2003. 
14. Yang YX, Lewis JD, Epstein S, Metz DC. Long-term proton pump inhibitor therapy and risk of hip fracture. JAMA 296: 29472953, 2006

15. Targownik LE, Lix LM, Metge CJ, Prior HJ, Leung S, Leslie WD. Use of proton pump inhibitors and risk of osteoporosisrelated fractures. CMAJ 179: 319-326, 2008.

16. Targownik LE, Lix LM, Leung S, Leslie WD. Proton-pump inhibitor use is not associated with osteoporosis or accelerated bone mineral density loss. Gastroenterology 138: 896-904, 2010.

17. Wayman J, Hayes N, Griffin SM. The response of early gastric cancer to proton-pump inhibitors. N Engl J Med 338: 1924-1925, 1998.

18. Wayman J, Hayes N, Raimes SA, Griffin SM. Prescription of proton pump inhibitors before endoscopy. A potential cause of missed diagnosis of early gastric cancers. Arch Fam Med 9: 385-388, 2000.

19. Lodato F, Azzaroli F, Turco L, et al. Adverse effects of proton pump inhibitors. Best Pract Res Clin Gastroenterol 24: 193-201, 2010.

20. Gaglia MA Jr. Torguson R, Hanna N, et al. Relation of proton pump inhibitor use after percutaneous coronary intervention with drug-eluting stents to outcomes. Am J Cardiol 105: 833-838, 2010.

21. Ho PM, Maddox TM, Wang L, et al. Risk of adverse outcomes associated with concomitant use of clopidogrel and proton pump inhibitors following acute coronary syndrome. JAMA 301: 937944, 2009.

22. Sibbing D, Morath T, Stegherr J, et al. Impact of proton pump inhibitors on the antiplatelet effects of clopidogrel. Thromb Haemost 101: 714-719, 2009.

23. Kwok CS, Loke YK. Meta-analysis: the effects of proton pump inhibitors on cardiovascular events and mortality in patients receiving clopidogrel. Aliment Pharmacol Ther 31: 810-823, 2010.

24. Talley NJ, American Gastroenterological. Association. American Gastroenterological Association medical position statement: evaluation of dyspepsia. Gastroenterology 129: 1753-1755, 2005.

25. Talley NJ, Vakil N, Practice Parameters Committee of the American College of Gastroenterology. Guidelines for the management of dyspepsia. Am J Gastroenterol 100: 2324-2337, 2005.

26. Anonymous ASHP Therapeutic Guidelines on Stress Ulcer Prophylaxis. ASHP Commission on Therapeutics and approved by the ASHP Board of Directors on November 14, 1998. Am J Health Syst Pharm 56: 347-379, 1999.
27. Lanza FL. A guideline for the treatment and prevention of NSAID-induced ulcers. Members of the Ad Hoc Committee on Practice Parameters of the American College of Gastroenterology. Am J Gastroenterol 93: 2037-2046, 1998.

28. Sebastian SS, Kernan N, Qasim A, O'Morain CA, Buckley M. Appropriateness of gastric antisecretory therapy in hospital practice. Ir J Med Sci 172: 115-117, 2003.

29. Scagliarini R, Magnani E, Pratico A, Bocchini R, Sambo P, Pazzi P. Inadequate use of acid-suppressive therapy in hospitalized patients and its implications for general practice. Dig Dis Sci 50: 2307-2311, 2005.

30. Pillans PI, Kubler PA, Radford JM, Overland V. Concordance between use of proton pump inhibitors and prescribing guidelines. Med J Aust 172: 16-18, 2000

31. Naunton M, Peterson GM, Bleasel MD. Overuse of proton pump inhibitors. J Clin Pharm Ther 25: 333-340, 2000.

32. Mayet AY. Improper use of antisecretory drugs in a tertiary care teaching hospital: an observational study. Saudi J Gastroenterol 13: 124-128, 2007.

33. Mat Saad AZ, Collins N, Lobo MM, O'Connor HJ. Proton pump inhibitors: a survey of prescribing in an Irish general hospital. Int J Clin Pract 59: 31-34, 2005.

34. George CJ, Korc B, Ross JS. Appropriate proton pump inhibitor use among older adults: a retrospective chart review. Am J Geriatr Pharmacother 6: 249-254, 2008.

35. Choudhry MN, Soran H, Ziglam HM. Overuse and inappropriate prescribing of proton pump inhibitors in patients with Clostridium difficile-associated disease. QJM 101: 445-448, 2008.

36. van Vliet EP, Otten HJ, Rudolphus $\mathrm{A}$, et al. Inappropriate prescription of proton pump inhibitors on two pulmonary medicine wards. Eur J Gastroenterol Hepatol 20: 608-612, 2008.

37. Thomas L, Culley EJ, Gladowski P, Goff V, Fong J, Marche SM. Longitudinal analysis of the costs associated with inpatient initiation and subsequent outpatient continuation of proton pump inhibitor therapy for stress ulcer prophylaxis in a large managed care organization. J Manag Care Pharm 16: 122-129, 2010.

38. Seite F, Delelis-Fanien AS, Valero $\mathrm{S}$, et al. Compliance with guidelines for proton pump inhibitor prescriptions in a department of geriatrics. J Am Geriatr Soc 57: 2169-2170, 2009.

39. Hughes JD, Tanpurekul W, Keen NC, Ee HC. Reducing the cost of proton pump inhibitors by adopting best practice. Qual Prim Care 17: 15-21, 2009.

\footnotetext{
(C) 2010 The Japanese Society of Internal Medicine http://www.naika.or.jp/imindex.html
} 